\title{
Smart and Functional Materials for Lithium-Ion Battery
}

\author{
C. M. Costa ${ }^{1,2, *(\mathbb{D})}$ and S. Lanceros-Mendez ${ }^{3,4, *(\mathbb{D})}$ \\ 1 Center of Physics, University of Minho, 4710-057 Braga, Portugal \\ 2 Institute of Science and Innovation for Bio-Sustainability (IB-S), University of Minho, 4710-053 Braga, Portugal \\ 3 BCMaterials, Basque Center for Materials, Applications and Nanostructures, UPV/EHU Science Park, \\ 48940 Leioa, Spain \\ 4 IKERBASQUE, Basque Foundation for Science, 48009 Bilbao, Spain \\ * Correspondence: cmscosta@fisica.uminho.pt (C.M.C.); senentxu.lanceros@bcmaterials.net (S.L.-M.)
}

Citation: Costa, C.M.;

Lanceros-Mendez, S. Smart and

Functional Materials for Lithium-Ion

Battery. Energies 2021, 14, 7713.

https://doi.org/10.3390/en14227713

Received: 5 November 2021

Accepted: 15 November 2021

Published: 18 November 2021

Publisher's Note: MDPI stays neutral with regard to jurisdictional claims in published maps and institutional affiliations.

Copyright: (c) 2021 by the authors. Licensee MDPI, Basel, Switzerland. This article is an open access article distributed under the terms and conditions of the Creative Commons Attribution (CC BY) license (https:// creativecommons.org/licenses/by/ $4.0 /)$.

\section{Introduction}

Climate change and energy dependence are nowadays critical issues that the world is facing, requiring effective and urgent actions to properly address them in a timely fashion. These issues are related to a strong dependence on fossil fuels, resulting from the increased mobility of population, industry, and energy consumption. In fact, energy and climate change are included in the United Nations agenda, in goals number 7 and 13 of 17 of the "Objectives for Sustainable Development" until 2030, in the scope of the affordable and clean energy and climate action goals, respectively, demanding efforts to improve decarbonization and the reduction of greenhouse gas emissions.

One of the ways to reduce dependence on fossil energy sources is to increase and promote the use of renewable energy combined with energy storage systems, as has already been adopted by different countries. Lithium-ion batteries represent the most suitable energy storage systems for a wide range of applications, including small electronic devices, smartphones, laptops, electric vehicles, or even home storage systems. However, considering their increasing use and implementation, there is a growing demand for advanced materials to improve battery performance (energy/power density, extended lifetime, conversion efficiency), decrease cost, improve safety, and reduce environmental impact. Some of these advanced materials are based on smart and (multi)functional materials for different battery components (electrodes and separators/solid polymer electrolytes), allowing one to optimize component and interface morphology and physico-chemical processes, as well as to provide additional complementary functions, such as self-sensing and self-healing characteristics. Thus, smart and (multi)functional materials are among the classes of materials with suitable and promising characteristics for the next generation of materials with a specific, tailorable, active, and controllable response to improving battery performance.

In this scope, in the following, we provide a brief account of the review, and research published papers in this Special Issue, divided by materials for electrodes and solid polymer electrolytes.

\section{A Short Review of the Contributions of This Special Issue}

The Special Issue contains a review paper and five research papers on lithium- and sodium-ion batteries.

The review paper [1] provides an overview of the latest advances of materials for lithium-ion batteries. Recent developments and materials for all components (electrodes, separators, solid polymer electrolytes) of lithium-ion batteries are present, together with the future trends in this field. It is also indicated that continued efforts are needed to improve materials, and that advanced materials are required for the new generation of these lithium-ion batteries.

The research papers in this Special Issue include active materials for electrodes and solid-state electrolytes (SSE). 
Carbonaceous materials are widely used for anodes electrodes, and one of the works [2] demonstrates the functionalizing/doping of mesoporous carbon (N-CMK-8) with nitrogen for lithium-ion batteries. This active material shows $\sim 1000 \mathrm{mAh} \cdot \mathrm{g}^{-1}$ at $0.1 \mathrm{~A} \cdot \mathrm{g}^{-1}$ and retains $\sim 200 \mathrm{mAh} \cdot \mathrm{g}^{-1}$ at the fast rate of $5 \mathrm{~A} \cdot \mathrm{g}^{-1}$. The strategy is highly promising for improving anode performance for the next generation of batteries.

In relation to active materials for cathode electrodes, one contribution is related to $\mathrm{LiAl}_{0.1}$ $\mathrm{Mn}_{1.9} \mathrm{O}_{4}$ (LAMO) [3], and another to $\mathrm{Li}_{1.33} \mathrm{MnTiO}_{4+\mathrm{z}}\left(0.8 \mathrm{LiMnTiO}_{4} \bullet 0.2 \mathrm{Li}_{2} \mathrm{Mn}_{0.5} \mathrm{Ti}_{0.5} \mathrm{O}_{3}\right)$ [4].

In order to solve the issues on capacity fading and the Jahn-Teller distortion of spinel $\mathrm{LiMn}_{2} \mathrm{O}_{4}$, the authors developed a new active material based on $\mathrm{LiAl}_{0.1} \mathrm{Mn}_{1.9} \mathrm{O}_{4}$ with a titanium nitride (TiN) coating layer via magnetron sputtering [3]. This new active material has proven to be capable for enhancing the cathode performance in LIBs, the coating layer promoting electron transport to the inner active material.

The contribution from $\mathrm{Vu}$ et al. [4] presents the spinel-layered cathode material $\mathrm{Li}_{1.33} \mathrm{MnTiO}_{4+\mathrm{z}}$ synthetized by the sol-gel technique, where the relationships between synthesis temperature, structure, and the electrochemical performance of the cathodes were evaluated. This active material shows a high capacity of 222 and $170 \mathrm{mAh} \cdot \mathrm{g}^{-1}$ at C/10 and $1 C$, respectively, and a capacity retention of $90.5 \%$ after 100 cycles.

In addition, this Special Issue also presents a research article on active material for sodium ion batteries. The active material is sodium manganite $\left(\mathrm{NaMnO}_{2}\right)$ and the work presents experimental and density functional theory calculations [5]. It was demonstrated that the monoclinic phase $\left(\alpha-\mathrm{NaMnO}_{2}\right)$ shows better electrochemical reversibility for the sodium intercalation reaction in comparison to the orthorhombic phase $\left(\beta-\mathrm{NaMnO}_{2}\right)$.

Finally, considering that thermal issues are strongly relevant for LIBs applications, a world is presented addressing the thermal conductivity for three types of solid state electrolytes (SSE): $\mathrm{Li}_{7} \mathrm{La}_{3} \mathrm{Zr}_{2} \mathrm{O}_{12}$ (LLZO), $\mathrm{Li}_{1.5} \mathrm{Al}_{0.5} \mathrm{Ge}_{1.5}\left(\mathrm{PO}_{4}\right)_{3}(\mathrm{LAGP})$, and $\mathrm{Li}_{1.3} \mathrm{Al}_{0.3} \mathrm{Ti}_{1.7}\left(\mathrm{PO}_{4}\right)_{3}(\mathrm{LATP})$ [6]. The authors determine that the thermal conductivity is $0.470 \pm 0.009 \mathrm{WK}^{-1} \mathrm{~m}^{-1}, 0.5 \pm 0.2 \mathrm{WK}^{-1} \mathrm{~m}^{-1}$ and $0.49 \pm 0.02 \mathrm{WK}^{-1} \mathrm{~m}^{-1}$ for LLZO, LAGP, and LATP respectively, where the thermal conductivity of these SSEs is higher than for electrolyte-soaked separators.

\section{Conclusions}

The contents and topics of this Special Edition are extremely relevant to modern society, which needs an energy transition to a more sustainable but still high-performance model, lithium-ion batteries playing a key role in this transition. Continued efforts are needed to develop advanced smart and functional materials for electrodes and separators / solid polymer electrolytes to support the application requirements of LIBs as an alternative to commonly used materials and/or address their current limitations. These new advanced materials must be based on sustainable approaches, either in materials and/or processes, with reduced ecological footprint and high performance.

Author Contributions: The authors contributed equally to this work. All authors have read and agreed to the published version of the manuscript.

Funding: The authors thank the Fundação para a Ciência e Tecnologia (FCT) for financial support under the framework of Strategic Funding grants UID/FIS/04650/2021, UID/EEA/04436/2021, and UID/QUI/0686/2021 and under projects POCI-01-0145-FEDER-028157 and PTDC/FIS-MAC/28157/ 2017 funded by national funds through FCT and by the ERDF through the COMPETE2020-Programa Operacional Competitividade e Internacionalização (POCI). The authors also thank the FCT for financial support under FCT investigator contract 2020.04028.CEECIND (C.M.C.). Financial support from the Basque Government Industry Department under the ELKARTEK program is acknowledged.

Acknowledgments: The authors thank MDPI Publisher for inviting them to be guest editors of this Special Issue, and the whole "Energies" editorial team, with special thanks to Addison Su as Managing Editor for his co-operation and patience. We would like to give special thanks to colleagues of Center of Physics at the University of Minho (http:/ / www.cf-um-up.pt/) and BCMaterials (www.bcmaterials.net) in the field of research in Electroactive Smart Materials (https://www.esmg.pt), for the interesting collaborative work, inspiring discussions and an exceptional working environment. 
Conflicts of Interest: The authors declare no conflict of interest.

\section{References}

1. Barbosa, J.C.; Gonçalves, R.; Costa, C.M.; Lanceros-Mendez, S. Recent advances on materials for Lithium-Ion batteries. Energies 2021, 14, 3145. [CrossRef]

2. Calcagno, G.; Agostini, M.; Xiong, S.; Matic, A.; Palmqvist, A.E.C.; Cavallo, C. Effect of nitrogen doping on the performance of mesoporous CMK-8 carbon anodes for Li-Ion batteries. Energies 2020, 13, 4998. [CrossRef]

3. Angelopoulou, P.; Kassavetis, S.; Papavasiliou, J.; Karfaridis, D.; Słowik, G.; Patsalas, P.; Avgouropoulos, G. Enhanced performance of $\mathrm{LiAl}_{0.1} \mathrm{Mn}_{1.9} \mathrm{O}_{4}$ cathode for Li-Ion battery via tin coating. Energies 2021, 14, 825. [CrossRef]

4. Vu, N.H.; Dao, V.-D.; Tran Huu, H.; Im, W.B. Effect of synthesis temperature on structure and electrochemical performance of spinel-layered $\mathrm{Li}_{1.33} \mathrm{MnTiO}_{4+z}$ in Li-Ion batteries. Energies 2020, 13, 2962. [CrossRef]

5. Manzi, J.; Paolone, A.; Palumbo, O.; Corona, D.; Massaro, A.; Cavaliere, R.; Muñoz-García, A.B.; Trequattrini, F.; Pavone, M.; Brutti, S. Monoclinic and orthorhombic $\mathrm{NaMnO}_{2}$ for secondary batteries: A comparative study. Energies 2021, 14, 1230. [CrossRef]

6. Bock, R.; Onsrud, M.; Karoliussen, H.; Pollet, B.G.; Seland, F.; Burheim, O.S. Thermal gradients with sintered solid state electrolytes in Lithium-Ion batteries. Energies 2020, 13, 253. [CrossRef] 